\title{
The Assignment Problem in Human Resource Project Management under Uncertainty
}

\author{
Helena Gaspars-Wieloch
}

check for

updates

Citation: Gaspars-Wieloch, Helena. 2021. The Assignment Problem in Human Resource Project Management under Uncertainty. Risks 9: 25. https://doi.org/10.3390/ risks9010025

Received: 29 November 2020 Accepted: 7 January 2021 Published: 12 January 2021

Publisher's Note: MDPI stays neutral with regard to jurisdictional clai$\mathrm{ms}$ in published maps and institutional affiliations.

Copyright: () 2021 by the author. Licensee MDPI, Basel, Switzerland. This article is an open access article distributed under the terms and conditions of the Creative Commons Attribution (CC BY) license (https:// creativecommons.org/licenses/by/ $4.0 /)$.
Department of Operations Research and Mathematical Economics, Poznań University of Economics and Business, 61-875 Poznań, Poland; Helena.gaspars@ue.poznan.pl

\begin{abstract}
The assignment problem (AP) is a discrete and combinatorial problem where agents are assigned to perform tasks for efficiency maximization or cost (time) minimization. AP is a part of human resource project management (HRPM). The AP optimization model, with deterministic parameters describing agent-task performance, can be easily solved, but it is characteristic of standard, well-known projects realized in a quiet environment. When considering new (innovation or innovative) projects or projects performed in very turbulent times, the parameter estimation becomes more complex (in extreme cases, even the use of the probability calculus is not recommended). Therefore, we suggest an algorithm combining binary programming with scenario planning and applying the optimism coefficient, which describes the manager's nature (attitude towards risk). The procedure is designed for one-shot decisions (i.e., for situations where the selected alternative is performed only once) and pure strategies (the execution of a weighted combination of several decision variants is not possible).
\end{abstract}

Keywords: assignment problem; human resource project management; uncertainty and risk; innovative and innovation projects; turbulent times; mathematical model and optimization

\section{Introduction}

\subsection{The Assignment Problem as an Element of Human Project Resource Management}

The assignment problem (AP) is broadly known as a deterministic and combinatorial problem in operations research, discrete optimization, and project management (Ahuja et al. 1993; Boros and Hammer 2003; Moder and Elmaghraby 1978; Panayiotopoulos 1981; Ravindran et al. 1987; Ravindran 2008). AP constitutes a significant issue in human resource project management (HRPM), which, according to the PMI (Project Management Institute), is one out of ten project management areas. HRPM includes human resource plan development, project team acquirement, project team development, and project team management (control). The goal of AP is to assign agents (usually workers) to perform tasks (usually jobs) and to maximize total efficiency or minimize entire cost/time. In the literature, the assignment problem is also called maximum-weight matching and is treated as a special case of the transportation problem. AP is used, for instance, in education (Faudzi et al. 2018), medicine (Trilling et al. 2007), rail transport (Piu and Speranza 2014), production planning, and telecommunication (Singh et al. 2012).

\subsection{From Deterministic AP to AP under Uncertainty-Motivation of the Research}

AP requires formulating and solving a binary optimization model, which is not time-consuming in the case of deterministic parameters describing agent-task performance. Nevertheless, decision-making under certainty within HRPM is only characteristic of standard, well-known projects realized in a quiet environment. In practice, such projects do not occur very often, especially nowadays (Barbieri et al. 2020; Samson 2020). That is why we focus, in this paper, on new projects (innovative or innovation projects) and projects performed in very stormy periods (e.g., economic crisis, pandemic, 
unstable law). We assume that "innovative projects are projects managed on the basis of new methods, while innovation projects bring new products and new services" (Spalek 2016). In such circumstances, we ought to refer to tools enabling uncertainty modeling (Lin et al. 2019; Midler et al. 2016; Narayanan et al. 2019; Oehmen et al. 2020; Pich et al. 2002; Singh and Rani 2019; Vats et al. 2019). Uncertainty may be defined in many ways (GasparsWieloch 2018); however, in this paper, we assume that it occurs when at least one parameter of the decision problem is not deterministic (Gaspars-Wieloch 2019a, 2019b, 2020b, 2021). Hence, the main motivation of the research is to focus on the assignment problem in the context of totally new projects developed in very dynamic surroundings because such cases are quite frequent nowadays.

\subsection{The Gap in the Literature}

Researchers have already analyzed the assignment problem with uncertain parameters (Derman et al. 1972; Ding 2020; Dhodiya and Tailor 2016; Ding and Zeng 2018; Krokhmal and Pardalos 2009; Zhang and Peng 2013). Their methods are based on probabilities, randomization, or fuzziness; here, we would like to apply scenario planning (SP), which is very popular among scientists and practitioners (Hoffmann 2017; Mietzner and Reger 2005; Schoemaker 1995). Scenario planning, as well as probabilities, randomization, or fuzziness, can be used to handle and model uncertainty, but SP brings more advantages due to its simplicity (Durbach 2014). Furthermore, it does not require any information on likelihood, which is desired in the case of projects with a high degree of novelty and a fast-evolving environment. As a matter of fact, SP has already been combined with AP in situations where the decision-maker is a strong pessimist (e.g., Aissi et al. 2005; Deineko and Woeginger 2006; Wu et al. 2018). In this paper, instead of probability calculus, we intend to make use of optimism/pessimism coefficients. These parameters enable us to describe the decision maker's (project manager's) nature, i.e., his/her expectations, predictions, attitude towards risk, and his/her state of mind/soul. These parameters have already been applied to other issues in numerous papers (Ciullo et al. 2019; Ellsberg 1961, 2001; Fuchs et al. 2019; Hernández et al. 2018; Hurwicz 1952; Jagodziński 2014; Liu and Ma 2020; Perez et al. 2015). Hence, the gap identified in the literature consists of the lack of methods designed for AP under uncertainty, which

- $\quad$ would be easy to use for managers,

- $\quad$ would not require such data that are too difficult to estimate in the case of projects with a high degree of novelty and a fast-evolving environment (like fuzzy numbers, probabilities),

- $\quad$ would be useful for any kind of decision-maker (pessimists, moderate decisionmakers, and optimists)

The goal of this paper is to bridge the gap by formulating a proper model and developing a suitable procedure for the aforementioned problem.

\subsection{The Structure of the Paper}

The paper contains the following parts. Section 2 briefly presents the essence of the original version of the assignment problem. It also enumerates selected extensions of $\mathrm{AP}$, discusses chosen uncertain factors connected with human resource project management, and describes the features of scenario planning in the context of the uncertain assignment problem and new projects. Section 3 contains the description of a novel algorithm for AP under uncertainty, with some illustrative examples. The procedure presented in the article combines binary programming with scenario planning. It is designed for one-shot decisions (i.e., decisions chosen for only one execution) and pure strategies (i.e., strategies where only one decision variant is chosen, not a combination of them). Section 4 discusses the characteristics of the new procedure. Section 5 contains conclusions. 


\section{Materials and Methods}

\subsection{Basic Variants of the Deterministic Assignment Problem}

Within the deterministic version of the assignment problem, there are a number of agents $(m)$ and a number of tasks $(n)$. Each agent-task assignment is described by parameter $e_{i, j}, t_{i, j}$, or $c_{i, j}$ denoting the performance (efficiency, time, or cost) connected with agent $A_{i}$ and task $T_{j}$. The agents may be assigned to perform any task. Table 1 presents the assignment problem on the assumption that the efficiency parameters are given.

Table 1. The assignment problem with efficiency parameters.

\begin{tabular}{cccccc}
\hline \multirow{2}{*}{ Agent } & \multicolumn{5}{c}{ Task } \\
\cline { 2 - 6 } & $\boldsymbol{T}_{\mathbf{1}}$ & $\ldots$ & $\boldsymbol{T}_{j}$ & $\ldots$ & $\boldsymbol{T}_{\boldsymbol{n}}$ \\
\hline$A_{1}$ & $e_{1,1}$ & $\ldots$ & $e_{1, j}$ & $\ldots$ & $e_{1, n}$ \\
$\vdots$ & $\vdots$ & $\ddots$ & $\vdots$ & $\ddots$ & $\vdots$ \\
$A_{i}$ & $e_{i, 1}$ & $\vdots$ & $e_{i, j}$ & $\vdots$ & $e_{i, n}$ \\
$\vdots$ & $\vdots$ & $\ddots$ & $\vdots$ & $\ddots$ & $\vdots$ \\
$A_{m}$ & $e_{m, 1}$ & $\ldots$ & $e_{m, j}$ & $\ldots$ & $e_{m, n}$ \\
\hline$A_{i}$-agent $I ; T_{j}$ - task $j ; m$-number of agents; $n$-number of tasks; $e_{i, j}$ - efficiency connected with agent $A_{i}$ and
\end{tabular}
task $T_{j}$. Source: Prepared by the author.

There are numerous variants of AP. The first one (AP-1a) maximizes the total efficiency of the assignment. Additionally, to accomplish all the tasks, it is required to assign exactly one agent to each job and exclusively one task to each worker (any agent can be assigned to perform any job, one at a time). The model for AP-1a is presented below:

$$
\begin{gathered}
\sum_{i=1}^{m} \sum_{j=1}^{n} e_{i, j} x_{i, j} \rightarrow \max \\
\sum_{i=1}^{m} x_{i, j}=1, \quad j=1, \ldots, n \\
\sum_{j=1}^{n} x_{i, j}=1, \quad i=1, \ldots, m \\
x_{i, j} \in\{0,1\}, \quad i=1, \ldots, m ; j=1, \ldots, n
\end{gathered}
$$

where $x_{i, j}$ is the binary variable. It is equal to 1 if task $T_{j}$ is performed by agent $A_{i}$.

In the second and third problems (AP-2a, AP-3a), the constraints do not change. The only modification is seen in the objective function, which minimizes the total time (5) for AP-2a or the entire cost (6) for AP-3a. Hence, problem AP-2a includes Equations (2)-(4) and (5), and problem AP-3a consists of Equations (2)-(4) and (6).

$$
\begin{aligned}
& \sum_{i=1}^{m} \sum_{j=1}^{n} t_{i, j} x_{i, j} \rightarrow \min \\
& \sum_{i=1}^{m} \sum_{j=1}^{n} c_{i, j} x_{i, j} \rightarrow \min
\end{aligned}
$$

In the models given above, it is assumed that $n=m$. However, if $n>m$, Equation (3) must be replaced with Formula (7):

$$
a_{i} \leq \sum_{j=1}^{n} x_{i, j} \leq b_{i}, \quad i=1, \ldots, m
$$


where $a_{i}$ and $b_{i}$ signify the minimal desired and maximal possible number of tasks that can be executed by particular agents.

This observation entails the necessity of distinguishing three other AP models: AP-1b (Equations (1), (2), (4) and (7)), AP-2b (Equations (2), (4), (5) and (7)), and AP-3b (Equations (2), (4), (6) and (7)).

Sometimes, the project managers are interested in objectives other than the goals mentioned above (Ahuja et al. 1993). If they tend to maximize the efficiency of the least efficient worker, the model should include the following objective function (Equation (8)) and an additional constraint (Equation (9)):

$$
\begin{gathered}
e \rightarrow \max \\
\sum_{j=1}^{n} e_{i, j} x_{i, j} \geq e, \quad i=1, \ldots, m
\end{gathered}
$$

Such a problem (i.e., AP-1a(e)) occurs only if $n=m$, so it must contain Equations (2)-(4), (8) and (9).

On the other hand, if the manager intends to minimize the time (or cost) of the slowest (the most expensive) worker, the model should include the following objective function (Equation (10) or (12)) and an additional constraint (Equation (11) or (13)):

$$
\begin{gathered}
t \rightarrow \min \\
\sum_{j=1}^{n} t_{i, j} x_{i, j} \leq t, \quad i=1, \ldots, m \\
c \rightarrow \min \\
\sum_{j=1}^{n} c_{i, j} x_{i, j} \leq c, \quad i=1, \ldots, m
\end{gathered}
$$

Hence, we can enumerate two other models: AP-2a(t) with Equations (2)-(4), (10) and (11), and AP-3a(c) with Formulas (2)-(4), (12) and (13).

The assignment problem (regardless of the variant of the deterministic optimization model) can be solved thanks to lpSolve, R, TORA (Temporary-Ordered Routing Algorithm), LINDO (Linear, Interactive and Discrete Optimization), AMPL (A Mathematical Programming Language), GAMS (General Algebraic Modeling System), CPLEX (an optimization software package with implements the simplex method and other decision problems in the C programming language), SAS/OR (Analytics Software and Solustions for Operations Research), and other optimization tools. They deliver an optimal or suboptimal solution depending on the size of the problem (number of variables, number of constraints).

Diverse algorithms also exist, such as the Hungarian method (Kuhn 1955, 1956; Martello 2010), which is a combinatorial optimization procedure for AP. Tkatek et al. (2016) referred to the multiple knapsack approach and used the genetic algorithm to solve the assignment problem of human resources.

\subsection{Selected Extensions of the Deteministic Assignment Problem}

The assignment problem under certainty has been extended by many researchers. For instance, Panayiotopoulos (1981) investigated a personnel assignment with a budget constraint. He emphasized that the essence of AP is not only to hire individuals and match jobs and candidates according to a given function but also to "provide education and development to the employees with regard to the present (short-term) and future (long-term) needs of the firm". This problem is also described in Panayiotopoulos and Papoulias (1979). Toroslu and Arslanoglu (2007) developed a genetic algorithm for AP with multiple objectives, which means that particular solutions are assessed on the basis of more than one criterion. In Chen and $\mathrm{Lu}$ (2007), we find the description of the assignment problem 
considering multiple inputs and outputs. The authors employed DEA (data envelopment analysis) and introduced a composite efficiency index. Hachicha et al. (2012) focused on AP under competencies and preferences constraints. They developed a hybridization of the bee algorithm and the immune system. Tkatek et al. (2013) presented a metaheuristical approach to solving spatial AP in a multisite enterprise. Such a problem consists of "moving employees from one site to another based on one or more criteria". Similar issues were discussed in Tkatek et al. (2015), where the authors combined the flowgraph approach (to model and construct the space solution) and the genetic approach (to investigate the optimal plan in the space solution). Recently, Jain et al. (2020) developed a priority-based unbalanced time minimization assignment problem for projects executed in two stages (some primary jobs are supposed to be completed within the first stage and the remaining jobs may be commenced after primary job completion).

\subsection{Uncertainty in HRPM-From Probabilities and Fuzzy Numbers to Scenario Planning}

When analyzing the assignment problem within HRPM, it is desirable to take uncertainty factors into consideration since the majority of parameters required to find the optimal solution are difficult to estimate. The data concerning the agent-task performance are usually burdened with errors. The time necessary to accomplish a task by a given worker may vary since his or her experience, abilities, health, physical fitness, mental capabilities, and efficiency can change. Furthermore, agent-task performance also depends on external factors such as weather, customer behavior, supplier delays, quality of raw materials, and machine reliability.

Scientists have already partially explored that area. For example, Krokhmal and Pardalos (2009) "present an overview of results and developments in the field of probabilistic assignment problems". The paper written by Derman et al. (1972) is concerned with "the optimal assignment of the $n$ men to the $n$ jobs so as to maximize the total expected reward". Dhodiya and Tailor (2016) presented a genetic algorithm to solve "a fuzzy multiobjective assignment problem by using an exponential membership function in which the coefficient of the objective function is described by a triangular possibility distribution". Other fuzzy models for AP are described, for instance, in Biswas and Pramanik (2011), Lin and Wen (2004), Li et al. (2012), Kagade and Bajaj $(2009,2010)$, and Gupta et al. (2013).

Durbach and Stewart (2012) enumerated diverse techniques that enable the handling of uncertainty, such as fuzzy numbers, probabilities, probability-like quantities, and explicit risk measures. Additionally, the papers described in the previous paragraph are only related to probabilities or fuzziness. However, in the opinion of Durbach and Stewart (2012), "uncertainties become increasingly so complex that the elicitation of those measures becomes operationally difficult for decision-makers to comprehend and virtually impossible to validate". Therefore, they encourage us to set scenarios describing "possible ways in which the future might unfold", and that is why, in this paper, we focus on the methods that integrate scenario planning (SP) into AP.

Scenario planning is a tool willingly applied to the decision-making process. It is very useful when dealing with issues under uncertainty, i.e., "situations where at least one parameter of the decision problem is not deterministic" (Gaspars-Wieloch 2019a, 2020b, 2021). "The ability to predict future economic events is undoubtedly crucial to the maintenance of successful business activities" (Aras et al. 2017). SP gives the opportunity to identify risks understood as "uncertain and uncontrolled factors influencing the consequences of the chosen options". It is helpful to companies, futurists, government planners, scientific communities, military analysts, and educational institutions (Gaspars-Wieloch 2019a, 2021; Mietzner and Reger 2005; Ringland 2006). Chermack et al. (2001), Pomerol (2001), and Wright and Goodwin (1999) have provided diverse definitions of the term scenario as well as numerous guidelines concerning proper scenario construction. Project managers really appreciate SP's benefits since it allows one to "analyze problems in a more deterministic way (Schoemaker 1995) than, for example, continuous probability distributions or fuzzy numbers". 
In this paper, we would like to apply scenario planning to the following HRPM areas. As was already mentioned, the data concerning parameters $e_{i, j}, t_{i, j}$, or $c_{i, j}$ are one of those that may be nondeterministic in the assignment problem (other uncertain information can be related, for instance, to the number of available workers or the number of significant tasks, but such aspects are not taken into consideration in our research). Let us recall that these coefficients describe the performance (efficiency, time, or cost) connected with agent $A_{i}$ and task $T_{j}$. Usually, they can be treated as deterministic data, but, in the paper, we mainly investigate the case of new projects (innovative or innovation projects) and projects performed in very stormy periods (e.g., economic crisis, pandemic, tense political situation, lack of raw materials, unforeseen fluctuations in demand, unstable law). In such circumstances, the performance of a given task depends not only on the employees' competence, skills, physical fitness, and mental capabilities but also on numerous additional internal (ability to cope with stressful situations, ability to cope with failure, openness to changes, creativity) and external factors (technology, regulations, demand).

If we assume that

1. the number of agents and tasks is known;

2. the characteristics describing the agent-task performance are uncertain;

3. the experts are able to define possible scenarios concerning performance quality;

4. the number of scenarios for particular cases (agent-task) may be different (the sets of scenarios are independent),

The uncertain efficiency assignment problem can be presented in the form of Table 2. Note that it is possible to include both deterministic and nondeterministic parameters, depending on the experts' knowledge and the environment's features.

Table 2. Uncertain assignment problem with efficiency parameters.

\begin{tabular}{|c|c|c|c|c|c|}
\hline \multirow{2}{*}{ Agent } & \multicolumn{5}{|c|}{ Task } \\
\hline & $T_{1}$ & $\ldots$ & $T_{j}$ & $\ldots$ & $T_{n}$ \\
\hline$A_{1}$ & $\begin{array}{l}e_{1,1(a)} ; e_{1,1(b)} \\
e_{1,1(c) ;} e_{1,1(d)}\end{array}$ & $\cdots$ & $e_{1, j}$ & $\cdots$ & $\begin{array}{c}e_{1, n(a) ; 1, n(b)} \\
e_{1, n(c)}\end{array}$ \\
\hline$\vdots$ & $\vdots$ & $\ddots$ & $\vdots$ & $\ddots$ & $\vdots$ \\
\hline$A_{i}$ & $e_{i, 1}$ & $\vdots$ & $e_{i, j(a) ;} e_{i, j(b)}$ & $\vdots$ & $\begin{array}{l}e_{i, n(a) ;} e_{i, n(b)} ; \\
e_{i, n(c) ;} e_{i, n(d)} ; \\
e_{i, n(e) ;} e_{i, n(f)} ;\end{array}$ \\
\hline$\vdots$ & $\vdots$ & $\ddots$ & $\vdots$ & $\ddots$ & $\vdots$ \\
\hline$A_{m}$ & $e_{m, 1(a)} ; e_{m, 1(b)}$ & $\ldots$ & $e_{m, j}$ & $\ldots$ & $e_{m, n}$ \\
\hline
\end{tabular}

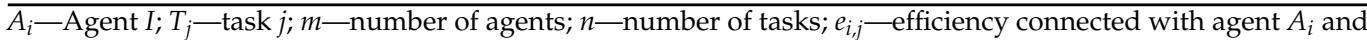
task $T_{j}$. Source: Prepared by the author.

\subsection{Should Scenario Planning be Applied with Probabilities?}

It is worth underlining that scientists "evaluate the role of probability distribution in SP depending on different aspects such as the essence of scenario planning, the individual or group decision-making, the facilitation in decision-making, the flexibility in decisionmaking" (Gaspars-Wieloch 2019a). Some researchers recommend using probabilities in SP (Millett 2009; Ravindran et al. 1987). According to Millett (2009), this application is justified if the following conditions are satisfied:

1. there are enough resources, budget, and time to prepare analytical scenarios with assigned probabilities;

2. "the corporate culture prefers quantitative or quasi-quantitative procedures to purely qualitative reasoning";

3. "the scenario team is familiar with the concept of Bayesian probabilities". 
When SP is combined with likelihood, it is required to estimate, after defining possible scenarios, the probability of the occurrence of each of them and calculate the expected values.

Nevertheless, Durbach (2019) stressed that the scenarios should not be regarded as the states of nature because "the set of scenarios does not constitute a complete probability spacethe scenario "likelihoods" are not probabilities in a statistical sense" (Stewart et al. 2013). Moreover, "the states of nature are mutually exclusive and exhaustive ... [and] are constructed from the same underlying dimensions", which is not the case of scenarios. Furthermore, probability does not have one unanimous and universal definition, which makes probability estimation quite complex and complicated (Gaspars-Wieloch 2018, 2019a, 2021).

Of course, we admit that if there are strong similarities between a given project and some previous projects already accomplished, one can set possible scenarios and even probabilities related to them; however, if there are very few common features, the use of probabilities seems to be unjustified. In the case of innovative and innovation projects, which are so original that historical data can only be used to a limited extent, we do not recommend probability calculus application but suggest an algorithm based on scenario planning and the optimism coefficient, which can constitute a probability-like measure. The second reason why we do not refer directly to probabilities results from the fact that we focus on one-shot decisions, i.e., decisions chosen for only one execution. When projects characterized with a high degree of novelty and uncertainty are analyzed, multishot decisions (i.e., options executed many times) are not justified since, after the first performance, the decision-maker (manager) may want to update his/her preferences and predictions (Postek et al. 2019).

\section{Results}

\subsection{AP Algorithm under Uncertainty-Applications and Steps}

In this section, a new AP algorithm under uncertainty will be presented. The novel approach can be applied under the following circumstances and for the following purposes:

1. The number of tasks and agents is known and deterministic. Depending on the problem, the worker is supposed to execute one task or several tasks, but, in each case, the work is performed by one agent only.

2. The tasks are independent, which means that the performance of a given task does not affect the performance of other tasks.

3. At least one agent-task performance is described by means of nondeterministic parameters.

4. The set of scenarios for each uncertain agent-task performance can be different since it may depend on different factors.

5. The algorithm is designed for one-shot decisions (projects) and pure strategies (i.e., strategies where only one decision variant is chosen, not a combination of them).

6. The decision-maker (manager) can declare his/her state of mind and soul (predictions) on the basis of optimism $(\beta)$ and pessimism $(\alpha)$ coefficients that reflect the attitude towards risk within a given problem. $\beta$ is close to one for extreme optimists and close to zero for extreme pessimists. These parameters may be different for each agent-task performance. Note that the sum of the pessimism coefficient and the optimism coefficient is equal to one $(\alpha+\beta=1)$, and both parameters belong to the interval $[0,1]$.

7. The aforementioned parameters are used to calculate the so-called $\mathrm{H}+\mathrm{B}$ index for each nondeterministic agent-task performance (that measure is briefly explained below).

8. The final optimization model is solved after transforming the initial scenario parameters into weighted values.

9. The algorithm allows us to find a solution to all the optimization problems presented in Section 2.1. 
10. The method gives the possibility of changing the final solution in the case of toohigh standard deviations connected with the chosen assignments. A high standard deviation indicates a significant dispersion of estimated scenario results, which is treated as an unwanted feature.

The H + B index has been proposed and described by Gaspars-Wieloch (2014a, 2015a, 2015b, 2017). It combines some features of two different decision rules: the Hurwicz rule (Hurwicz 1952) and the Bayes (Laplace) rule. The first rule applies the pessimism and optimism coefficients to compute a weighted value; however, it is worth stressing that this measure is only determined by extreme payoffs (the highest one and the lowest one); the Hurwicz rule does not take into account intermediate values and their possible asymmetry. It ignores the frequency of particular payoffs. On the other hand, the Bayes rule considers the values estimated for each scenario, but this time, every outcome obtains the same weight since the Bayes index constitutes an arithmetical average of all the results. Hence, we can observe some limitations in both procedures. The use of the first rule may lead to illogical recommendations, especially in the case of asymmetric payoffs (GasparsWieloch 2014b); the second rule does not give the opportunity to include information on the decision-maker's (DM's) nature (Gaspars-Wieloch 2020a). In connection with the conclusions formulated above, the $\mathrm{H}+\mathrm{B}$ rule (a hybrid of the Hurwicz and Bayes rules) has been worked out so that each scenario value can be taken into consideration; the procedure may be useful to different types of decision-makers.

The $\mathrm{H}+\mathrm{B}$ index is calculated in the following way:

1. For optimists $(\beta>0.5)$, the optimism coefficient is multiplied by the best value and the pessimism coefficient is multiplied by all the remaining outcomes. All the products are added. Then, the weighted value is divided by the sum of all the applied coefficients.

2. For pessimists $(\alpha>0.5)$, the pessimism coefficient is multiplied by the worst value and the optimism coefficient is multiplied by all the remaining outcomes. All the products are added. Then, the weighted value is divided by the sum of all the applied coefficients.

3. For moderate DMs $(\alpha=\beta=0.5)$, it is possible to use any formula described above since the $\mathrm{H}+\mathrm{B}$ index is equal to the Bayes index in this case.

Such reasoning enables us to consider each predicted payoff and assign the highest weight to the result that is the one most expected by the decision-maker.

The AP algorithm under uncertainty consists of the steps enumerated below:

1. Define the target, the set of agents, the set of tasks, the constraints, and the possible scenarios for the particular uncertain agent-task performance.

2. Estimate the optimism and pessimism coefficients for each nondeterministic agenttask performance.

3. Apply the $\mathrm{H}+\mathrm{B}$ rule separately for each uncertain agent-task performance.

4. Formulate the optimization model using $\mathrm{H}+\mathrm{B}$ indices.

5. Solve the model.

6. If the recommended assignments are connected with too-high standard deviations, correct the solution by eliminating the recommended assignment with the highest standard deviation and solving a new amended optimization model.

\subsection{Illustrative Examples}

\section{EXAMPLE 1}

Let us analyze each step of the algorithm on the basis of the following example. Assume that the project manager (PM) is supposed to start an innovation project (development of a totally new online computer game), but the surrounding and future situations are quite uncertain (e.g., in 2020: epidemic, constant changes in government regulations, increase in unemployment, the bankruptcy of numerous companies, reduction of the mobility of the population). 
The development process involves preproduction, production, and postproduction processes, and each of them consists of numerous stages (e.g., high concept, pitch, prototype, design, programming, art production, testing); in this article, we explore only a specific step. We assume that the manager is currently analyzing one stage of the whole aforementioned project- the first testing. He has already planned the human resources needed (what skills are needed for particular tasks, how many workers does he have, what are their competences). He has stated that the number of available agents (8) is sufficient for this stage. Within this phase, the tasks which are supposed to be done are independent- the performance of any particular task does not affect the performance of the remaining ones, but all tasks must be completed before the commencement of the next stage of the project. On the one hand, the project is very promising since, due to many restrictions, people are forced to stay at home, avoid meetings with people, and avoid going to the cinema-this means they may have more time for online computer games. Nevertheless, the success of the project really depends on the workers' effectiveness. They have very sophisticated skills. If one of them gets sick (e.g., coronavirus) or cannot spend enough time on the project (e.g., in connection with school closures and the necessity to work and look after children simultaneously), the quality of the final product may suffer significantly. Fortunately, if a given agent is not able to continue particular activities, there is an opportunity to partially reorganize the initial assignment since the workers may perform more than one job (but only one at a time).

The project manager receives a table prepared by the experts, representing the efficiency parameters for each agent-task performance (Table 3). They have been estimated on the basis of similar (but not analogical!) tasks executed within previous projects. Therefore, in some cases, single parameters are replaced (unfortunately) by a list of possible efficiencies. We see that each worker is capable of executing particular activities, but their efficiency depends significantly on the nature of the work.

Table 3. Efficiency data.

\begin{tabular}{|c|c|c|c|c|c|c|c|c|c|c|}
\hline $\mathrm{A} / \mathrm{T}$ & T1 & $\mathrm{T} 2$ & T3 & $\mathrm{T} 4$ & T5 & T6 & T7 & $\mathrm{T} 8$ & T9 & T10 \\
\hline A1 & $\begin{array}{l}10,11 \\
15,18\end{array}$ & 4 & 7 & $\begin{array}{c}1,6,9 \\
12,17 \\
24\end{array}$ & 11 & 14 & $\begin{array}{l}8,9, \\
25\end{array}$ & $\begin{array}{c}15,18 \\
25\end{array}$ & 22 & 5 \\
\hline A2 & 6 & 15 & 8 & 7 & $\begin{array}{l}15,25 \\
30,35\end{array}$ & 2 & 1 & 20 & $\begin{array}{c}13,14 \\
15\end{array}$ & $\begin{array}{r}3,9 \\
10,11\end{array}$ \\
\hline A3 & $\begin{array}{c}3,4,8 \\
9,10\end{array}$ & $\begin{array}{c}2,5 \\
10\end{array}$ & $\begin{array}{c}9,13 \\
26\end{array}$ & 19 & 16 & 10 & 10 & 8 & $\begin{array}{r}3,7 \\
15,25\end{array}$ & $\begin{array}{c}1,5 \\
10,16\end{array}$ \\
\hline A4 & 6 & 8 & 1 & 10 & 16 & 19 & 25 & $\begin{array}{c}6,8 \\
16,18 \\
25\end{array}$ & $\begin{array}{c}3,4,7 \\
9,15\end{array}$ & $\begin{array}{l}14,15, \\
17,19\end{array}$ \\
\hline A5 & 3 & $\begin{array}{c}3,8 \\
17,18 \\
30\end{array}$ & $\begin{array}{l}1,4,7 \\
10,18\end{array}$ & $\begin{array}{l}24,25 \\
27,30\end{array}$ & 20 & 18 & 15 & $\begin{array}{c}22,25 \\
26\end{array}$ & 20 & 15 \\
\hline A6 & 24 & 15 & 21 & 7 & $\begin{array}{l}15,25 \\
30,40\end{array}$ & $\begin{array}{l}20,21, \\
22,23\end{array}$ & 5 & 25 & $\begin{array}{c}13,14 \\
20\end{array}$ & $\begin{array}{r}3,12 \\
13,16\end{array}$ \\
\hline A7 & 15,25 & 30 & 4 & 5 & 2 & 7 & $\begin{array}{l}12,15, \\
18,20\end{array}$ & 2 & 6 & 2 \\
\hline A8 & 34,36 & $\begin{array}{l}22,23, \\
24,25\end{array}$ & 40 & 8 & 7 & 2 & 9 & $\begin{array}{c}1,2,3 \\
4\end{array}$ & $\begin{array}{c}19,20 \\
25\end{array}$ & 23 \\
\hline
\end{tabular}

Source: Prepared by the author.

The specificity of particular tasks is different, so the primary units applied to measure efficiency are also different for each job (e.g., number of standard cases tested within $1 \mathrm{~h}$, number of new features tested within $1 \mathrm{~h}$, number of unusual situations tested within $1 \mathrm{~h}$ ). That is why the initial data were not comparable and had to be normalized in the form of points (from 0 to 40), as gathered in Table 3. 
The PM intends to assign the most appropriate people to particular works. He is interested in total efficiency maximization. Each task ought to be completed by one agent. The workers are allowed to perform at least one job, but no more than three (Step 1).

The project manager knows each member of the team. Hence, he is able to define different optimism coefficients for each uncertain agent-task performance, but he decides to declare the level of this value separately for each worker (i.e., for each row in the table). They are equal to $0.3,0.3,0.4,0.4,0.5,0.5,0.9$, and 0.9 , respectively (Step 2).

Now, each uncertain parameter has to be transformed into the H + B index (Step 3, Table 4).

Table 4. Hurwicz and Bayes $(\mathrm{H}+\mathrm{B})$ indices.

\begin{tabular}{ccccccccccc}
\hline A/T & T1 & T2 & T3 & T4 & T5 & T6 & T7 & T8 & T9 & T10 \\
\hline A1 & 12.63 & 4.00 & 7.00 & 9.59 & 11.00 & 14.00 & 12.15 & 18.00 & 22.00 & 5.00 \\
A2 & 6.00 & 15.00 & 8.00 & 7.00 & 23.44 & 2.00 & 1.00 & 20.00 & 13.69 & 6.94 \\
A3 & 6.45 & 5.14 & 15.00 & 19.00 & 16.00 & 10.00 & 10.00 & 8.00 & 11.44 & 7.22 \\
A4 & 6.00 & 8.00 & 1.00 & 10.00 & 16.00 & 19.00 & 25.00 & 13.82 & 7.18 & 16.00 \\
A5 & 3.00 & 15.20 & 8.00 & 26.50 & 20.00 & 18.00 & 15.00 & 24.33 & 20.00 & 15.00 \\
A6 & 24.00 & 15.00 & 21.00 & 7.00 & 27.50 & 21.50 & 5.00 & 25.00 & 15.67 & 11.00 \\
A7 & 24.00 & 30.00 & 4.00 & 5.00 & 2.00 & 7.00 & 18.75 & 2.00 & 6.00 & 2.00 \\
A8 & 35.80 & 24.50 & 40.00 & 8.00 & 7.00 & 2.00 & 9.00 & 3.50 & 24.00 & 23.00 \\
\hline
\end{tabular}

Source: Prepared by the author.

Let us see how the first value (12.63) is calculated:

$$
h b_{1,1}=[0.7 \times 10+0.3 \times(11+15+18)] /(0.7+3 \times 0.3)=12.63
$$

The next step (Step 4) consists of model formulating. We do not present the whole model since it contains 80 decision variables (e.g., $x_{2,3}$ equals 1 if Agent A2 performs task $\mathrm{T} 3$, and 0 otherwise), one objective function (with 80 products), 8 constraints concerning the agents, 10 constraints related to the tasks and 80 variable constraints. We only show a reduced version of the objective function, the first agent condition, and the first task condition (decision variables are binary).

$$
\begin{gathered}
\text { Function : } 12.63 x_{1,1}+4.00 x_{1,2}+\cdots+23.00 x_{8,10} \rightarrow \max \\
\text { Constraint }(1): 1 \leq x_{1,1}+x_{1,2}+\cdots+x_{1,10} \leq 3 \\
\text { Constraint }(9): x_{1,1}+x_{2,1}+\cdots+x_{8,1}=1
\end{gathered}
$$

The solution has been obtained by SAS/OR, which is an optimization software (Step 5). The results are given in Table 5. The maximal total expected efficiency equals 264.07, but let us emphasize that it is only an estimated value (the real one may be different since it depends on the scenarios that will occur for particular agent-work performances). As we see, Agents A1-A7 are supposed to execute one task; Worker A8 has to perform three works.

Within Step 6, it is possible to amend the solution if some selected assignments are characterized by a considerable dispersion of estimated efficiencies and there is another available assignment with a lower dispersion. In our case, the highest dispersion (among the chosen assignments), which could be replaced by a lower one, occurs for A2-T5, but let us assume that the project manager accepts such a standard deviation level (i.e., 8.54). If he wanted to modify the plan, a new optimization model would be solved with an additional constraint: $x_{2,5}=0$ (such a constraint should also be added for all the potential agent-job assignments characterized by a standard deviation level equal to at least 8.54). Then again, the PM would have the opportunity to accept the solution or to change it. 
Table 5. Optimal assignments (total expected efficiency maximization).

\begin{tabular}{ccccccccccc}
\hline A/T & T1 & T2 & T3 & T4 & T5 & T6 & T7 & T8 & T9 & T10 \\
\hline A1 & 0 & 0 & 0 & 0 & 0 & 0 & 0 & 0 & 1 & 0 \\
A2 & 0 & 0 & 0 & 0 & 1 & 0 & 0 & 0 & 0 & 0 \\
A3 & 0 & 0 & 0 & 1 & 0 & 0 & 0 & 0 & 0 & 0 \\
A4 & 0 & 0 & 0 & 0 & 0 & 0 & 1 & 0 & 0 & 0 \\
A5 & 0 & 0 & 0 & 0 & 0 & 0 & 0 & 1 & 0 & 0 \\
A6 & 0 & 0 & 0 & 0 & 0 & 1 & 0 & 0 & 0 & 0 \\
A7 & 0 & 1 & 0 & 0 & 0 & 0 & 0 & 0 & 0 & 0 \\
A8 & 1 & 0 & 1 & 0 & 0 & 0 & 0 & 0 & 0 & 1 \\
\hline
\end{tabular}

Source: Prepared by the author.

\section{EXAMPLE 2}

As was already mentioned, the algorithm enables us to find the solution for each optimization model presented in Section 2.1.

If

- the PM is interested in maximizing the efficiency of the least efficient worker,

- $\quad$ the problem involves 8 agents (A1-A8 from Table 3) and 8 jobs (T1-T8 from Table 3),

- $\quad$ it is required that all tasks be accomplished by assigning exactly one agent to each task and exclusively one job to each agent,

the objective function, the first agent condition, the first agent efficiency condition, and the first task constraint (decision variables are binary) would be as follows:

$$
\text { Function }: e \rightarrow \max
$$

$$
\text { Constraint (1): } x_{1,1}+x_{1,2}+\cdots+x_{1,8}=1
$$

Constraint (9) : $12.63 x_{1,1}+4.00 x_{1,2}+\cdots+18.00 x_{1,8} \geq e$

$$
\text { Constraint (17): } x_{1,1}+x_{2,1}+\cdots+x_{8,1}=1
$$

For the solution presented in Table 6, the individual expected agent efficiencies are equal to $18.00,23.44,19.00,25.00,18.00,21.00,30.00$, and 35.8, respectively. Hence, the efficiency of the least efficient worker equals 18 . This time again, there is an assignment with high dispersion, A2-T5. If necessary, the plan can be modified by solving the same model with an additional condition $x_{2,5}=0$ and similar conditions for each potential assignment with a dispersion not lower than 8.54. It is up to the project manager to evaluate the first solution and possibly change it.

Table 6. Optimal assignments (expected efficiency maximization of the least efficient worker).

\begin{tabular}{ccccccccc}
\hline A/T & T1 & T2 & T3 & T4 & T5 & T6 & T7 & T8 \\
\hline A1 & 0 & 0 & 0 & 0 & 0 & 0 & 0 & 1 \\
A2 & 0 & 0 & 0 & 0 & 1 & 0 & 0 & 0 \\
A3 & 0 & 0 & 0 & 1 & 0 & 0 & 0 & 0 \\
A4 & 0 & 0 & 0 & 0 & 0 & 0 & 1 & 0 \\
A5 & 0 & 0 & 0 & 0 & 0 & 1 & 0 & 0 \\
A6 & 0 & 0 & 1 & 0 & 0 & 0 & 0 & 0 \\
A7 & 0 & 1 & 0 & 0 & 0 & 0 & 0 & 0 \\
A8 & 1 & 0 & 0 & 0 & 0 & 0 & 0 & 0 \\
\hline
\end{tabular}

Source: Prepared by the author.

\section{Discussion}

Let us analyze the algorithm in detail.

(1) According to Point 5 presented in Section 3.1, the goal of the new algorithm is to indicate the best pure strategy (not mixed strategy). In the context of the assignment 
problem, a pure strategy occurs when particular jobs are entirely assigned to one worker. However, as mentioned in Section 3.2, sometimes a given agent might not finish the task due to numerous possible chance events (e.g., illness). In such circumstances, the initial optimal assignment plan has to be updated by assigning the rest of the job to another agent. Note that the new strategy should still fulfill the constraints of the primary model (i.e., the maximal number of tasks for particular agents must not be exceeded). Imagine that Agent A8 has just accomplished T1 and T10. He has also executed a part of Task T3. Unfortunately, he is not able to continue this activity due to some unexpected events. Hence, the PM may assign the rest of Task T3 to A6 because A6 has executed only one activity and, among the remaining agents, this worker is the best for Task T3. A6-T3 performance is worse than the A8-T3, so total expected efficiency will certainly decrease; however, the dispersion connected with A6-T3 is equal to 0, which means that its efficiency is guaranteed. Note that when the plan has to be modified during project realization at moment $t$, total expected efficiency may be calculated as the sum of the real efficiency observed from the beginning of the project to $t$ and the expected efficiency related to the period starting at moment $t$ and ending with the project completion.

(2) According to Points 1 and 3, the only uncertainty factor considered in the algorithm is related to agent-work performance. This element is very often difficult to predict. Furthermore, depending on the agent-work case, particular performances can be determined by different aspects. That is why the procedure gives the opportunity to diversify the set of possible scenarios (Point 4) and the level of pessimism and optimism coefficients (point 6) for each agent-task performance. The possibility of applying diverse parameters is crucial since, in real problems, the PM may have a different perception of particular human abilities.

(3) In a sense, the AP algorithm under uncertainty is similar, for instance, to PERT (a project evaluation and review technique), which is a tool used in project time management (another area distinguished by PMI). PERT gives the opportunity to estimate three durations (pessimistic, most likely, optimistic) for each activity belonging to the project. The nondeterministic AP procedure also enables us to consider several scenarios, but this time (and this is a significant advantage), the number of possible scenarios for each agent-task performance may vary from 1 to any positive integer value (see Point 4 ).

(4) Note that the AP algorithm under uncertainty is not the first AP procedure referring to scenarios. Numerous papers have been devoted to the min-max assignment problem and the min-max regret assignment problem (e.g., Aissi et al. 2005; Deineko and Woeginger 2006; Wu et al. 2018), where the scenarios are also applied. However, the assumptions and methodology adopted in those papers differ significantly from the idea presented in this article. In the cited papers, the construction of the problem allows us only to analyze the case of decision-makers being extreme pessimists since the aim of the applied methods is to find "a solution with the best worst-case value across all scenarios" (which is characteristic of the Wald rule) or to find "a feasible solution minimizing, over all possible scenarios, the maximum deviation of the value of the solution from the optimal value of the corresponding scenario" (which is characteristic of the Savage rule). Here, the DM's attitude towards risk is taken into consideration in a quite simple way, and the use of the optimism coefficient enables us to solve the assignment problem for any decision-maker (pessimist, moderate, optimist). Additionally, the number of scenarios for each agent-task performance may be different, which is not the case for the procedures described in the aforementioned papers.

(5) The novel approach (similarly to the original AP algorithm) still enables the project manager to find the best assignment for various optimization models (see Point 9). He or she can focus on the following objectives: total efficiency maximization, entire cost/time minimization, maximization of the efficiency of the least efficient worker, 
minimization of the time of the lowest worker, or minimization of the cost of the most expensive worker. Note that in the case of a cost objective function, there is no need to take into consideration all the cost factors because some of them may be common for each worker. It is better to focus on the elements that differ for particular agents (e.g., remuneration).

(6) It is worth underlining that sometimes the optimization model may contain more than one optimal solution (i.e., solutions that have the best value of the objective function); however, when solving the model, only one optimal strategy is generated by the optimization tool. The remaining optimal plans may be obtained after subsequent use of this tool, but there is no guarantee that the whole set of optimal solutions will be found. Nevertheless, even if the manager does not know the number of optimal strategies and cannot generate all of them, such knowledge is not crucial in the decision-making process since each optimal plan satisfies all the constraints of the model and has the same level of objective function. The significant difference between particular optimal solutions may concern varied maximal dispersions, but Step 6 of the algorithm allows the DM to control this factor. If the dispersion connected with a given optimal solution is too high for the manager, there is an opportunity to generate a new strategy that does not contain the assignment with the unwanted dispersion level. Hence, if the optimization model consists of several optimal plans, and the DM is not willing to perform the first generated solution, Step 6 of the procedure can lead him or her to another optimal solution.

(7) Point 7 of the AP algorithm under uncertainty concerns the use of the $\mathrm{H}+\mathrm{B}$ index. Note that this measure gives the possibility of assigning the highest weight to the value that is the most expected; however, importantly, the remaining values connected with a given agent-task assignment are also considered because the less-essential weight is assigned to all of them. Such an approach enables the PM to control not only the extreme scenarios but each intermediate scenario as well, which is extremely vital when dealing with uncertainty. Let us add that thanks to the denominator of the $\mathrm{H}+\mathrm{B}$ index (being the sum of all the applied weights), the final $\mathrm{H}+\mathrm{B}$ measurement is never lower than the outcome of the worst scenario and never higher than the outcome of the best scenario.

\section{Conclusions}

When considering new projects (innovative or innovation projects) or projects performed in very turbulent times, human resource project management and optimization need nondeterministic models and algorithms. The method proposed in this contribution is designed for the assignment problem under uncertainty. It is based on binary programming and selected features of the Hurwicz and Bayes decision rules.

On the one hand, the novel approach is more complex than the deterministic procedure, but on the other hand,

- $\quad$ it allows the project managers to apply scenario planning (a relatively simple tool) to parameter estimation,

- it gives the opportunity to include information on the decision-maker's (manager's) nature (state of mind/soul) and attitude towards risk within a given problem-this is possible thanks to the pessimism and optimism coefficients, which are also used in other well-known decision rules),

- it does not require the use of objective probabilities (due to a high degree of uncertainty), and

- $\quad$ it enables the project managers to accept or correct the obtained solution (thanks to the standard deviation analysis).

In connection with all these observations, we recognize the numerous advantages of applying the AP algorithm under uncertainty to human resource project management. As a matter of fact, it may support each stage of HRPM, i.e., human resource plan development, project team acquirement, project team development, and project team management 
(control) since the suggested procedure requires defining the problem assumptions (which is significant in the first stages) and allows undertaking simulations (which can be helpful even in the last stage of HRPM). By changing selected parameters of the AP model (e.g., a given agent-task performance, the optimism coefficient, or the number of tasks that are supposed to be executed by particular workers), the project manager has the opportunity to analyze diverse plans and even modify strategies that have already been implemented.

The AP algorithm under uncertainty cannot be directly compared with existing procedures designed for nondeterministic situations since the majority of them refer to probabilities, fuzziness, and randomization, which are rather applied to problems with a lower degree of uncertainty than the cases investigated in this paper. A direct comparative analysis may be made only between the novel procedure and the methods based on scenario planning. Such approaches have already been developed, but their main limitations result from the fact that they can be used only by extreme pessimists, and they require an identical number of scenarios for each agent-task performance.

Hence, the first novelty of the study is the possibility of finding the optimal solution for any kind of decision-maker (extreme pessimist, moderate pessimist, moderate DM, moderate optimist, and extreme optimist) with a relatively easy tool-i.e., scenario planning. The second, but also very significant, novelty is the hybrid character of the new method, which combines binary programming with scenario planning, the Hurwicz rule, the Bayes rule, and standard deviation analysis. This combination enables the consideration of diverse decision-makers and allows managers without sophisticated mathematical skills to solve problems. The third novelty is related to the opportunity of assigning different sets of scenarios for a particular agent-task performance. The fourth original factor is connected with the applications of the suggested procedure-existing methods may support projects with a medium degree of novelty, while this approach has been developed for projects with a high degree of novelty.

The results of the research described in this paper have vital managerial implications. First, any manager's attitude towards risk may be taken into account, thanks to the presented procedure. Second, when applying the AP algorithm under uncertainty, the project manager does not need to acquire knowledge in the field of advanced mathematics. Third, the method allows the managers to analyze realistic projects as it is not based on the assumption that each agent-task performance must depend on the same set of scenarios. Fourth, thanks to the use of the $\mathrm{H}+\mathrm{B}$ rule (which is a combination of the Hurwicz measure and the Bayes measure), all the values connected with a given performance are taken into consideration (not only the extreme ones) - such an approach gives the manager a stronger sense of keeping control of the situation. Fifth, if the manager is not willing to accept the maximal standard deviation related to the optimal solution, he or she may modify the generated plan by including additional constraints and solving for a new model - this is possible thanks to the last step of the algorithm.

The current procedure is designed for independent agent-task performances, which, in the case of some real projects, can be treated as a limitation of the method. That is why a future direction for the conducted research could concern the extension of the algorithm for cases with dependent efficiencies, costs, or times. Other possible future directions are related to the use of an uncertain number of agents and tasks. In future research, it would also be desirable to extend the AP algorithm under uncertainty to applications mentioned in Section 2.2., especially to multicriteria decision-making, since managers often assess particular strategies on the basis of more than one criterion.

Funding: This research received no external funding.

Institutional Review Board Statement: Not applicable.

Informed Consent Statement: Not applicable.

Data Availability Statement: Not applicable.

Conflicts of Interest: The author declares no conflict of interest. 


\section{References}

Ahuja, Ravindra, Thomas Magnanti, and James Berger Orlin. 1993. Network Flows. Theory, Algorithms and Applications. Upper Saddle River: Prentice Hall.

Aissi, Hassene, Cristina Bazgan, and Daniel Vanderpooten. 2005. Complexity of the min-max and min-max regret assignment problems. Operations Research Letters 33: 634-40. [CrossRef]

Aras, Serkan, Ipek Deveci Kocakoc, and Cigdem Polat. 2017. Comparative study on retail sales forecasting between single and combination methods. Journal of Business Economics and Management 18: 803-32. [CrossRef]

Barbieri, Paolo, Albachiara Boffelli, Stefano Elia, Luciano Fratocchi, Matteo Kalchcshmidt, and Danny Samson. 2020. What can we learn about reshoring after Covid-19? Operations Management Research 13: 131-36. [CrossRef]

Biswas, Pranab, and Surapati Pramanik. 2011. Multi-objective assignment problem with fuzzy costs for the case of military affairs. International Journal of Computer Applications 30: 7-12. [CrossRef]

Boros, Endre, and Peter L. Hammer. 2003. Discrete Optimization. Amsterdam: Elsevier, vol. 11.

Chen, Liang-Hsuan, and Hai-Wen Lu. 2007. An extended assignment problem considering multiple inputs and outputs. Applied Mathematical Modelling 31: 2239-48. [CrossRef]

Chermack, Thomas, Susan Lynham, and Wendy Ruona. 2001. A review of scenario planning literature. Future Research Quarterly 17: 7-31.

Ciullo, Alessio, Karin De Bruijn, Jan Kwakkel, and Frans Klijn. 2019. Systematic Flood Risk Management: The Challenge of Accounting for Hydraulic Interactions. Water 11: 2530. [CrossRef]

Deineko, Vladimir, and Gerhard Woeginger. 2006. On the robust assignment problem under fixed number of cost scenarios. Operations Research Letters 34: 175-79. [CrossRef]

Derman, Cyrus, Gerald Lieberman, and Sheldon Ross. 1972. A sequential stochastic assignment problem. Management Sciences 18: 349-55. [CrossRef]

Dhodiya, Jayesh, and Anita Ravi Tailor. 2016. Genetic algorithm based hybrid approach to solve fuzzy multi-objective assignment problem using exponential membership function. SpringerPlus 5: 2028. [CrossRef]

Ding, Sibo. 2020. Uncertain random quadratic bottleneck assignment problem. Journal of Ambitient Intelligence and Humanized Computing 11: 3259-64. [CrossRef]

Ding, Sibo, and Xiao-Jun Zeng. 2018. Uncertain random assignment problem. Applied Mathematical Modelling 56: 96-104. [CrossRef]

Durbach, Ian, and Theodor Stewart. 2012. Modeling uncertainty in multi-criteria decision analysis. European Journal of Operational Research 223: 1-14. [CrossRef]

Durbach, Ian. 2014. Outranking under uncertainty using scenarios. European Journal of Operational Research 232: 98-108. [CrossRef]

Durbach, Ian. 2019. Scenario Planning in the Analytic Hierarchy Process. Hoboken: Wiley.

Ellsberg, Daniel. 1961. Risk, ambiguity and Savage axioms. Quarterly Journal of Economics 75: 643-69. [CrossRef]

Ellsberg, Daniel. 2001. Risk, Ambiguity and Decision. New York: Garland Publishing.

Faudzi, Syakinah, Syariza Abdul-Rahman, and Rosshairy Abd Rahman. 2018. An assignment problem and its application in education domain: A review and potential path. Advances in Operations Research 2018: 8958393. [CrossRef]

Fuchs, Clemens, Karl Marquardt, Joachim Kasten, and Katharina Skau. 2019. Wind Turbines on German Farms-An Economic Analysis. Energies 12: 1587. [CrossRef]

Gaspars-Wieloch, Helena. 2014a. Propozycja hybrydy reguł Hurwicza i Bayesa w podejmowaniu decyzji w warunkach niepewności. Zeszyty Naukowe Uniwersytetu Ekonomicznego w Katowicach 178: 74-92.

Gaspars-Wieloch, Helena. 2014b. Modifications of the Hurwicz decision rules. Central European Journal of Operations Research 22: 779-94. [CrossRef]

Gaspars-Wieloch, Helena. 2015a. Modifications of the Omega ratio for decision making under uncertainty. Croatian Operational Research Review 6: 181-94. [CrossRef]

Gaspars-Wieloch, Helena. 2015b. Innovative products and newsvendor problem under uncertainty without probabilities. Paper presented at the 13th International Symposium of Operational Research SOR'2015, Bled, Slovenia, September 23-25; pp. 343-50.

Gaspars-Wieloch, Helena. 2017. Newsvendor problem under complete uncertanty-A case of innovative products. Central European Journal of Operations Research 25: 561-85. [CrossRef] [PubMed]

Gaspars-Wieloch, Helena. 2018. Podejmowanie Decyzji w Warunkach Niepewności_Planowanie Scenariuszowe i Wybrane Zastosowania Ekonomiczne. Poznań: Poznań University of Economics and Business.

Gaspars-Wieloch, Helena. 2019a. Role of scenario planning and probabilities in economic decision problems-Literature review and new conclusions. In Contemporary Issues in Business, Management and Economics Engineering'2019. Vilnius: VGTU Press, pp. 111-21. [CrossRef]

Gaspars-Wieloch, Helena. 2019b. Spare parts quantity problem under uncertainty-The case of entirely new devices with short life cycle. Multiple Criteria Decision Making 14: 5-28. [CrossRef]

Gaspars-Wieloch, Helena. 2020a. Critical analysis of classical scenario-based decision rules for pure strategy searching. Organizations and Management Series 149: 155-65.

Gaspars-Wieloch, Helena. 2020b. A new application for the Goal Programming-The Target Decision Rule for uncertain problems. Journal of Risk and Financial Management 13: 280. [CrossRef] 
Gaspars-Wieloch, Helena. 2021. Scenario planning combined with probabilities as a risk management tool-Analysis of pros and cons. International Journal of Economics and Business Research 21: 22-40. [CrossRef]

Gupta, Pankaj, Mukesh K. Mehlawat, and Garima Mittal. 2013. A fuzzy approach to multi-criteria assignment problem using exponential membership functions. International Journal of Machine Learning and Cybernetics 4: 647-57. [CrossRef]

Hachicha, Raoudha Mkaouar, El Mouloudi Dafaoui, and Abderrahman El Mhamedi. 2012. Assignment problem under competences and preferences constraints: Modelling and resolution. IFAC Proceedings Volumes 45: 1170-76. [CrossRef]

Hernández, Jose, Maria García, and Gilberto Hernández. 2018. Inventories control, state regulations and The Amplitude Model (TAM). In Handbook of Research on Promoting Business Process Improvement through Inventory Control Techniques. Edited by Nita M. Shah. Hershey: IGI Global, pp. 442-67. [CrossRef]

Hoffmann, Christian Hugo. 2017. Strengths and weaknesses of scenario planning as a risk management tool. In Assessing Risk Assessment. Wiesbaden: Springer Gabler, pp. 213-18.

Hurwicz, Leonid. 1952. A Criterion for Decision Making under Uncertainty. Technical Report 355. Prince: Cowles Commission.

Jagodziński, Jacek. 2014. The extended Hurwicz criterion for decision making in logistic applications. Zeszyty Naukowe Wyższej Szkoły Bankowej we Wroctawiu 1: 25-43.

Jain, Ekta, Kalpana Dahiya, and Vanita Verma. 2020. A priority based unbalanced time minimization assignment model. OPSEARCH 57: 13-45. [CrossRef]

Kagade, K. L., and V. H. Bajaj. 2009. Fuzzy approach with linear and some non-linear membership functions for solving multiobjective assignment problems. Advances in Computational Research 1: 14-17.

Kagade, K. L., and V. H. Bajaj. 2010. Fuzzy method for solving multi-objective assignment problem with interval cost. Journal of Statistics and Mathematics 1: 1-9.

Krokhmal, Pavlo, and Panos Pardalos. 2009. Random assignment problems. European Journal of Operational Research 194: 1-17. [CrossRef]

Kuhn, Harold. 1955. The Hungarian method for the assignment problem. Naval Research Logistics Quarterly 2: 83-97. [CrossRef]

Kuhn, Harold. 1956. Variants of the Hungarian method for assignment problems. Naval Research Logistics Quarterly 3: 253-58. [CrossRef]

Li, Fachao, Li Da Xu, Chenxia Jin, and Hong Wang. 2012. Study on solution models and methods for the fuzzy assignment problems. Expert Systems with Applications 39: 11276-83. [CrossRef]

Lin, Chi-Jen, and Ue Pyng Wen. 2004. A labeling algorithm for the fuzzy assignment problem. Fuzzy Sets and Systems 142: 373-91. [CrossRef]

Lin, Lin, Ralf Muller, Fangwei Zhu, and Hanwen Liu. 2019. Choosing suitable project control modes to improve the knowledge integration under different uncertainties. International Journal of Project Management 37: 896-911. [CrossRef]

Liu, Fan, and Ning Ma. 2020. Multicriteria ABC inventory classification using the Social Choice Theory. Sustainability 12: 182. [CrossRef]

Martello, Silvano. 2010. Jeno Egervary: From the origins of the Hungarian algorithm to satellite communication. Central European Journal of Operations Research 18: 47-58. [CrossRef]

Midler, Christophe, Catherine Killen, and Alexander Kock. 2016. Project and innovation management: Bridging contemporary trends in theory and practice. Project Management Journal 47: 3-7. [CrossRef]

Mietzner, Dana, and Guido Reger. 2005. Advantages and disadvantages of scenario approaches for strategic foresight. International Journal of Technology Intelligence and Planning 1: 220-39. [CrossRef]

Millett, Stephen. 2009. Should probabilities be used with scenarios. Journal of Futures Studies 13: 61-68.

Moder, Joseph, and Salah Elmaghraby. 1978. Handbook of Operations Research. New York: Van Nostrand Reinhold, vols. 2 and 3.

Narayanan, Sriram, Sridhar Balasubramanian, Jayashankar Swaminathan, and Ying Zhang. 2019. Managing uncertain tasks in technology-intensive project environments: A multi-method study of task closure and capacity management decisions. Journal of Operations Management 66: 260-80. [CrossRef]

Oehmen, Josef, Giorgio Locatelli, Morten Wied, and Pelle Willumsen. 2020. Risk, uncertainty, ignorance and myopia: Their managerial implications for B2B firms. Industrial Marketing Management 88: 330-228. [CrossRef]

Panayiotopoulos, John, and Demetrios Papoulias. 1979. The general problem of $\mathrm{m}$ persons and $\mathrm{n}$ positions for short- and long-term decision-making. Operational Research Society 30: 917-21. [CrossRef]

Panayiotopoulos, John. 1981. Personnel assignment with a budget constraint. In Productivity Analysis at the Organizational Level. Studies in Productivity Analysis. Edited by Nabil Adam and Ali Dogramaci. Dordrecht: Springer, vol. 3.

Perez, David, Jose Gilberto Hernández Ramirez, Maria García, and Gilberto Hernández. 2015. Hurwicz method modified and The Amplitude Model (TAM). In Exploring the Possibilities for Sustainable Future Growth in Business and Technology Management, Paper Presented at Seventeenth Annual International Conference, Peniche/Lisbon, Portugal, July 7-11. Edited by Nejdet Delener, Leonora Fuxman, Victor Lu and Susana Rodrigues. Peniche: GBATA, pp. 559-66.

Pich, Michael, Chritoph Loch, and Arnoud De Meyer. 2002. On uncertainty, ambiguity, and complexity in project management. Management Science 48: 1008-23. [CrossRef]

Piu, Francesco, and Grazia Speranza. 2014. The locomotive assignment problem: A survey on optimization models. International Transactions in Operational Research 21: 327-52. [CrossRef]

Pomerol, Jean-Charles. 2001. Scenario development and practical decision making under uncertainty. Decision Support Systems 31: 197-204. [CrossRef] 
Postek, Krzysztof, Dick den Hertog, Jarl Kind, and Chris Pustjens. 2019. Adjustable robust strategies for flood protection. Omega 82: 142-54. [CrossRef]

Ravindran, A., Don Phillips, and James Solberg. 1987. Operations Research: Principles and Practice, 2nd ed. Hoboken, NJ, USA: Wiley.

Ravindran, A. 2008. Operations Research and Management Science Handbook. Boca Raton, London and New York: CRS Press.

Ringland, Gill. 2006. Scenario Planning: Managing for the Future, 2nd ed. West Sussex: John Wiley \& Sons.

Samson, Danny. 2020. Operations/supply chain management in a new world context. Operations Management Research 13: 1-3. [CrossRef]

Schoemaker, Paul. 1995. Scenario planning: A tool for strategic thinking. Sloan Management Review 36: 25-40.

Singh, Sujeet, and Deepika Rani. 2019. A branching algorithm to solve binary problem in uncertain environment: An application in machine allocation problem. OPSEARCH 56: 1007-23. [CrossRef]

Singh, Shweta, G. Dubey, and Rajesh Shrivastava. 2012. A comparative analysis of assignment problem. IOSR Journal of Engineering 2: 1-15. [CrossRef]

Spalek, Seweryn. 2016. Innovative vs. innovation projects in organizations. In Innowacyjność Wspótczesnych Organizacji. Edited by Wszendybył Skulska Ewa. Toruń: TNOiK, pp. 226-37.

Stewart, Theodor, Simon French, and Jesus Rios. 2013. Integrating multicriteria decision analysis and scenario planning: Review and extension. Omega 41: 679-88. [CrossRef]

Tkatek, Said, Otman Abdoun, Jaafar Abouchabaka, and Najat Rafalia. 2013. A meta-heuristically approach of the spatial assignment problem of human resources in multi-sites enterprise. International Journal of Computer Applications 77. [CrossRef]

Tkatek, Said, Otman Abdoun, Jaafar Abouchabaka, and Najat Rafalia. 2015. A hybrid heuristic method to solve an assignment problem of human resource. International Review on Computers and Software 10. [CrossRef]

Tkatek, Said, Otman Abdoun, Jaafar Abouchabaka, and Najat Rafalia. 2016. A multiple knapsack approach for assignment problem of human resources. Journal of Theoretical and Applied Information Technology 87: 374.

Toroslu, Ismail Hakki, and Yilmaz Arslanoglu. 2007. Genetic algorithm for the personnel assignment problem with multiple objectives. Information Sciences 177: 787-803. [CrossRef]

Trilling, Lorraine, Alain Guinet, Dominique Le Magny, and Patrick Moullier. 2007. Modèle de Planification des Médecins Anesthésistes: Un Problème Multicritère. Trois-Rivières: 7ème Congrès International de Génie Industriel-CIGI.

Vats, Peeyush, Gunjan Soni, Ajay Rathore, and Surya Yadav. 2019. A demand aggregation approach for inventory control in two echelon supply chain under uncertainty. OPSEARCH 56: 840-68. [CrossRef]

Wright, George, and Paul Goodwin. 1999. Future-focused thinking: Combining scenario planning with decision analysis. Journal of Multi-Criteria Decision Analysis 8: 311-21. [CrossRef]

Wu, Wei, Manuel Iori, Silvano Martello, and Mutsunori Yagiura. 2018. Exact and heuristic algorithms for the interval min-max regret generalized assignment problem. Computers and Industrial Engineering 125: 98-110. [CrossRef]

Zhang, Bo, and Jin Peng. 2013. Uncertain programming model for uncertain optimal assignment problem. Applied Mathematical Modelling 37: 6458-68. [CrossRef] 